九州大学学術情報リポジトリ

Kyushu University Institutional Repository

\title{
Hydrogen behavior near surface regions in Mo and W studied by tritium tracer technique
}

\section{Hoshihira, Takamitsu}

Interdisciplinary Graduate School of Engineering Sciences, Kyushu University

\section{Otsuka, Teppei}

Interdisciplinary Graduate School of Engineering Sciences, Kyushu University

Wakabayashi, Ryusuke

Interdisciplinary Graduate School of Engineering Sciences, Kyushu University

Tanabe, Tetsuo

Interdisciplinary Graduate School of Engineering Sciences, Kyushu University

ht tp://hdl. handle. net/2324/25687

出版情報：Journal of Nuclear Materials. 417 (1/3)，pp.559-563，2011-10-01. Elsevier B.V. バージョン：

権利関係: (C) 2011 Elsevier B.V. 
[ID code] $\quad 00179$

\section{[Paper Title]}

\section{Hydrogen Behavior near Surface Regions in Mo and W \\ Studied by Tritium Tracer Technique}

[Authors and Affiliations]

Takamitsu Hoshihira ${ }^{1}$, Teppei Otsuka ${ }^{1}$, Ryusuke Wakabayashi ${ }^{1}$, Tetsuo Tanabe ${ }^{1 *}$

${ }^{1}$ ( Interdisciplinary Graduate School of Engineering Sciences, Kyushu University, Hakozaki 6-10-1, Higashi-Ku, Fukuoka-Shi, Fukuoka-Ken, Japan)

[Corresponding Author]

Name $\quad$ : Tetsuo Tanabe

Postal address : : Interdisciplinary Graduate School of Engineering Sciences,

Kyushu University Hakozaki 6-10-1, Higashi-Ku, Fukuoka-Shi,Fukuoka-Ken, Japan

Telephone number : +81-92-642-3795

Fax number $\quad:+81-92-642-3795$

E-mail address $\quad$ : tanabe@nucl.kyushu-u.ac.jp 


\section{Paper Title: Hydrogen Behavior near Surface Regions in Mo and W \\ Studied by Tritium Tracer Technique}

Takamitsu Hoshihira ${ }^{1}$, Teppei Otsuka ${ }^{1}$, Ryusuke Wakabayashi ${ }^{1}, \underline{\text { Tetsuo Tanabe }^{1}}$

${ }^{1}$ ( Interdisciplinary Graduate School of Engineering Sciences, Kyushu University, Hakozaki 6-10-1, Higashi-Ku, Fukuoka-Shi, Fukuoka-Ken, Japan)

\section{Abstract}

Tritium tracer techniques are applied to observe behavior of hydrogen (Tritium (T)) in near surface regions of Mo and $W$ loaded by gaseous absorption (GAS) and a glow discharge (GDC). GDC produces blisters on both Mo and W surfaces and tritium autoradiograph (TARG) showed the thickness of blister skins is larger than the escaping depth of T $\beta$-electrons, around 1 1 m. For GAS specimens, T evolution is likely controlled by diffusion giving diffusion coefficients of,

$$
\begin{array}{lll}
D_{M o}= & 1.5 \times 10^{-7} \exp \left(-\frac{41 \mathrm{~kJ} / \mathrm{mol}}{R T}\right) & \mathrm{m}^{2} \mathrm{~s}^{-1} \\
D_{W}= & 4.3 \times 10^{-9} \exp \left(-\frac{38 \mathrm{~kJ} / \mathrm{mol}}{R T}\right) \quad \mathrm{m}^{2} \mathrm{~s}-1
\end{array}
$$

at 273-323 K. GDC specimens show much smaller diffusion coefficients with higher activation energies and $T$ release continues very long, suggesting $T$ release from blisters.

Keywords:

Tungsten, Molybdenum, Hydrogen, Diffusion, Blistering, Trapping 


\section{Introduction}

It is well known that energetic hydrogen ion irradiation results in blistering and/or grains exfoliations of plasma facing materials of a fusion reactor [1-6]. However, the process and mechanism of these phenomena have not been well understood. In addition, hydrogen release kinetics on blistered surfaces of high $\mathrm{Z}$ plasma facing materials, which could directly relate to tritium retention and tritium safety, are not well understood, too. We have been applying Tritium Auto-RadioGraphy (TARG) to observe hydrogen behavior in blisters and surrounding area to clarify the blistering mechanisms and to understand how hydrogen is retained in plasma facing materials [7-8]. The previous study [8], using TARG for hydrogen blistering of Molybdenum (Mo), has clearly distinguished two different types of blistering mechanisms; one is hydrogen bubble coalescence to make surface blisters and the other is grain exfoliation due to hydrogen accumulation at grain boundaries and/or clustered defects due to brittle nature of Mo.

There still remains an important question. Does hydrogen stay long in or escape from the blisters? The blistering is caused by hydrogen accumulation to give a pressure of nearly GPa level or equivalent to the strength of materials. If there is no barrier on the inner surface of the blisters for hydrogen permeation nor hydrogen in the blisters is trapped with excess energy than solution, hydrogen should be easily released from the blisters. If the blister formation is caused by elastic deformation, the hydrogen release should force the blisters to return flat surface or to disappear. On the other hand, the blisters were caused by plastic deformation as observed in W [9], for instance, the blister shape should remain even after hydrogen released out.

To examine the hydrogen behavior after blister formation, we have applied TARG and Imaging Plate technique (IPT) for blistered surface of Mo and W by tritium loading and also examined hydrogen release behavior by applying a tritium tracer technique. Both techniques have been successfully applied for blistering phenomena in $\mathrm{Al}$ and $\mathrm{Mo}[7,8]$.

\section{Experimental}

Specimens used here were hot-rolled polycrystalline Mo and W sheets. The size of the sheets was $5 \times 10 \mathrm{~mm}^{2}$ with the thickness of $1 \mathrm{~mm}$. The surface of the specimens was mechanically polished with abrasive papers and mirror finish using $0.3 \mu \mathrm{m} \mathrm{Al}_{2} \mathrm{O}_{3}$ powder.

Tritium (T) was loaded by two different methods, (1) an alternate current glow discharge (AC-GDC) 
method with $\mathrm{H}_{2}$ gas pressure of $60 \mathrm{~Pa}$ containing $\mathrm{T}$ with $5.0 \times 10^{-6}$ in $\mathrm{T} / \mathrm{H}$ ratio to produce blisters on specimen surfaces (referred as GDC specimens) and (2) gaseous absorption at $673 \mathrm{~K}$ under a pressure either $0.27,1.3$ or $5.3 \mathrm{kPa}$ for $12 \mathrm{~h}$. After the exposure, the specimens were quenched into the liquid $\mathrm{N}_{2}$ temperature to avoid further migration of hydrogen in the specimen (referred as GAS specimens).

The $\mathrm{T}$ loaded specimen surfaces were observed by an optical microscope and a scanning electron microscope (SEM) and confirmed that the GDC specimens were blistered, while the GAS specimens had no blisters. For the GDC specimens, TARG and IPT were applied to observe hydrogen (T) profiles on the blistered surfaces. Details of TARG and IPT were given in elsewhere [7-10].

$\mathrm{T}$ release measurements were performed for both specimens. Immediately after the $\mathrm{T}$ loading, the specimens were immersed into a liquid scintillation cocktail (PerkinElmer, Ultima Gold) kept at a constant temperature between 298 and $358 \mathrm{~K}$ in water or oil bath. Integrated amounts of $\mathrm{T}$ released into the cocktail were measured by a liquid scintillation counter (PerkinElmer, Tri-Carb 2800) with a certain time interval until the tritium release was completed as shown in Fig. 2. This time sequence is referred as a $\mathrm{T}$ evolution curve hereafter.

\section{Results}

\section{3-1. TARG and IPT}

Figure 1 shows photographs of optical microscope for blistered surfaces on the GDC specimens of Mo. IP images, i.e. surface distribution of $\mathrm{T}$ immediately after the loading and 10 moths later are also given in the figure. One can see hemispherical blisters in an enlarged photograph. For T loaded Mo surface, as already reported in the previous paper [8], TARG was successfully done to show T accumulation in blisters and grain boundaries. For the $\mathrm{W}$ surfaces, in contrast, we have failed to observe TARG images which should show $\mathrm{T}$ accumulations in blisters and grain boundaries. This is a clear evidence for that the thickness of blister skins of $\mathrm{W}$ surface are thicker than the escaping depth of $\beta$ electron of $\mathrm{T}$ in $\mathrm{W}$ (around $1 \mu \mathrm{m})$. Since the range of implanted T by GDC is much less than $1 \mu \mathrm{m}$, T must be penetrated into deep to accumulate for bubble formation and blistering. Nevertheless the IP images clearly show surface segregation of $\mathrm{T}$ on $\mathrm{W}$. The space resolution of IP is too poor to distinguish $\mathrm{T}$ accumulated in blisters from $\mathrm{T}$ in solution or $\mathrm{T}$ absorption at surface. It should be noted that the surface still retained appreciable amount of T after 10 month later. Since T segregated on the surface is easily oxidized to OT or HTO and 
removed by replacing with $\mathrm{OH}$ or $\mathrm{H}_{2} \mathrm{O}$ in atmosphere, $\mathrm{T}$ must be continuously supplied from the inside for long time as discussed later.

\section{3-2 Tritium evolution after T loading}

\section{3-2-1 T loaded by gas absorption (GAS specimens)}

Tritium (T) evolutions (time sequences of evolved tritium from the specimen) for Mo and W GAS specimens are shown in Figs. 2 and 3, respectively. Suppose T was loaded homogenously, T diffusion coefficient was calculated applying a solution of one dimensional diffusion equation starting with the initially homogenous distribution [11],

$$
C(x, t)=\frac{4 C_{0}}{\pi} \sum_{j=0}^{\infty} \frac{1}{2 j+1} \sin \frac{(2 j+1) \pi x}{d} \exp \left[-\left(\frac{(2 j+1) \pi}{d}\right)^{2} D t\right],
$$

where, $C(x, t)$ is hydrogen concentration at a position $x$ and time $t, d$, the thickness of the specimens, $D$, diffusion coefficient, $\mathrm{C}_{0}$, the initial hydrogen concentration. And the surface boundary condition is $\mathrm{C}(0, \mathrm{t})=0$.

Accordingly, the amount of evolved hydrogen is calculated to be

$$
C_{\text {out }}(t)=C_{0}-\int C(x, t) d x=C_{0}\left[1-\frac{8}{\pi^{2}} \sum_{j=0}^{\infty} \frac{1}{(2 j+1)^{2}} \exp \left\{-\left(\frac{(2 j+1) \pi}{d}\right)^{2} D t\right\}\right]
$$

With using the least quares fitting method eq(2) was fitted to the experimental evolution curve to determine $\mathrm{C}_{0}$ and D. The fitting was very successful as shown in bold lines in figs.2 and 3. Apparent diffusion coefficients thus determined are plotted in Figs. 6 and 7 for Mo and W, respectively together with literature data.

\section{3-2-2 T loaded by GDC}

T evolution from Mo and W GDC specimens are shown in Figs. 4 and 5, respectively. Compared to the GAS specimens, the T evolution did not seem saturated and fittings with equation (2) were not successful. Applying cross-sectional observation by IPT for the GDC specimens, the depth profile of loaded $\mathrm{T}$ were visualized [12]. The results (not shown here) clearly indicated that $\mathrm{T}$ was localized within $50 \mu \mathrm{m}$ from the surface. Since space resolution of IP is about $50 \mu \mathrm{m}$, the actual depth might be a little less. 
Assuming the initial loaded $\mathrm{T}$ was homogeneously distributed within $50 \mu \mathrm{m}$ from the surface, Fick's diffusion equation was solved allowing $\mathrm{T}$ freely diffusing to both directions of deep inside and surface under the assumption of $\mathrm{C}(0, \mathrm{t})=0$. Thus calculated $\mathrm{T}$ release from the surface was fitted to the $\mathrm{T}$ evolution observed for the GDC Mo and W specimens to determine apparent diffusion coefficients. The best fit results are given as solid lines in Figs. 5 and 6 and obtained apparent diffusion coefficients are plotted in Fig. 7. As seen in the figure, the apparent diffusion coefficients for the GDC specimens were clearly smaller than those for the GAS specimens.

\section{3-3. Temperature dependence of diffusion coefficient}

In Figs. 6 and 7, diffusion coefficients determined here are compared to literature data for Mo [13-19] and W [19-22], respectively.

Temperature dependence of the diffusion coefficients for the GAS specimens of Mo and W are,

$$
\begin{aligned}
& \mathrm{D}_{\mathrm{Mo}}=1.5 \times 10^{-7} \exp \left(-\frac{41 \mathrm{~kJ} / \mathrm{mol}}{R T}\right) \quad \mathrm{m}^{2} \mathrm{~s}^{-1} \\
& \mathrm{D}_{\mathrm{W}}=4.3 \times 10^{-9} \exp \left(-\frac{38 \mathrm{~kJ} / \mathrm{mol}}{R T}\right) \mathrm{m}^{2} \mathrm{~s}^{-1} .
\end{aligned}
$$

Most of the diffusion data of Mo and $\mathrm{W}$ were determined at higher temperatures, and no direct comparison with the present ones are possible. Quite recently, Ikeda et al. [18] have measured diffusion coefficients of Mo and $\mathrm{W}$ by tritium permeation method at similar temperatures regions with the present work, which are very likely giving correct data and plotted in both figures. The present data are a little smaller than the Ikeda's data but has very near activation energies. This suggests that the present ones determined from the GAS specimens are for hydrogen in solution sites, but still could be influenced by trapping or surface oxidation. Because hydrogen dissolved at higher temperatures would result over saturation leading defect formation at quenching to liq. $\mathrm{N}_{2}$. Furthermore, surface oxidation could proceed during gas absorption.

The apparent diffusion coefficients for the GDC specimens were clearly lower than those for the GAS specimens. The near surface regions of the GDC specimens is likely damaged heavily and trapped hydrogen as appeared in blistering. Therefore, the diffusion coefficients were very likely influenced by such trapping to give smaller values. Hence the evolution data are refitted recombination limited desorption or second order release kinetics as shown as a bold line in Fig.8. One can see better agreement 
than that for the diffusion model (thin dotted line) in Fig. 8. This strongly supports that the evolution from the GDC specimen was influenced by trapping i.e. bubbles and blisters. The release, from the GDC specimen seems to continue far longer. As depicted in Fig. 2, the IP image of the GDC W specimen at 10 month after the loading still retained some $\mathrm{T}$ on the surface. If the surface $\mathrm{T}$ was retained as the form of OT without any additional supply from the bulk, most of them should be isotopically replaced by $\mathrm{H}_{\text {in }} \mathrm{H}_{2} \mathrm{O}$ of surrounding atmosphere. Therefore $\mathrm{T}$ supply from the bulk should be continued far longer than the evolution observed in Fig. 5.

It is well known that hydrogen implanted into $\mathrm{W}$ are accumulated in far deeper region than the project range of injected ions to make blisters [24]. Actually, as noted in the previous section, T loaded by GDC actually penetrated to more than $50 \mu \mathrm{m}$. All these suggest that the injected hydrogen by GDC was released by at least two different mechanisms, i.e. diffusional release of hydrogen in solution sites, which might not be involved in blistering, and delayed release of trapped hydrogen. Hydrogen once accumulated in the blisters seems to be released as well. The 2nd order desorption kinetics observed here might be a candidate process for hydrogen release from the blisters, but this needs a micro model for the process.

\section{Conclusion}

Tritium tracer techniques are successfully applied to observe behavior of hydrogen in near surface regions of Mo and W loaded by gaseous absorption (GAS) and glow discharge (GDC). For both metals, surface blisters were observed for GDC specimens, but not for GAS specimens. On the blistered surfaces, accumulation of tritium in or near blisters could not be observed by Tritium Auto-RadioGraphy (TARG). This indicates that the blister skins were too thick to allow tritium $\beta$-electron penetrating through the skins to be detected. Hydrogen (tritium) release behavior is clearly different between the GDC specimens and the GAS specimens. In the latter, hydrogen (T) evolution is likely controlled by diffusion giving apparent diffusion coefficients of Mo and W,

$$
\begin{aligned}
& \mathrm{D}_{\mathrm{Mo}}=1.5 \times 10^{-7} \exp \left(-\frac{41 \mathrm{~kJ} / \mathrm{mol}}{R T}\right) \quad \mathrm{m}^{2} \mathrm{~s}^{-1} \\
& \mathrm{D}_{\mathrm{W}}=4.3 \times 10^{-9} \exp \left(-\frac{38 \mathrm{~kJ} / \mathrm{mol}}{R T}\right) \mathrm{m}^{2} \mathrm{~s}^{-1}
\end{aligned}
$$

for temperatures ranging from $273 \mathrm{~K}$ to $323 \mathrm{~K}$. Both are very near to quite recently determined values of 
Mo and $\mathrm{W}$ by a gaseous permeation method under similar temperature region.

The apparent diffusion coefficients determined from the hydrogen evolution of the GDC specimens of Mo and W were significantly smaller than those for the GAS specimens with larger activation energies and hydrogen release continued very long, suggesting hydrogen detrapping from hydrogen blisters and other defects produced by GDC.

\section{Acknowledgement}

This work was partly supported by Grand-in-Aid for Scientific Research, Priority area 467, "Fusion Tritium". 


\section{References}

[1] S. Muto, T. Matsui, T. Tanabe, J. Nucl. Mater. 290-293 (2001) 131-134.

[2] S. Igarashi, S. Muto, T. Tanabe, J. Nucl. Mater., 307-311 (2002) 1126.

[3] W. M. Shu, G.-N. Luo, T. Yamanishi, J. Nucl. Mater. 367-370 (2007) 1463-1467.

[4] Y. Ueda, T. Funabiki, T. Shimada et al., J. Nucl. Mater. 337 (2005) 1010.

[5] M.Y. Ye, H. Kanehara, S. Fukuta, N. Ohno, S. Takamura, J. Nucl. Mater 313 (2003) 72.

[6] R. Checcetto, L. M. Gratton, A. Miotello, Surf. Coat. Technol. 158 (2002) 356.

[7] T. Hoshihira, T. Otsuka, T. Tanabe, J. Nucl. Mater. 386-388 (2009) 776-779

[8] T. Hoshihira, T. Otsuka, T. Tanabe, J. Nucl. Mater. 390-391 (2009) 1029-1031

[9] N. Enomoto, S. Muto, T. Tanabe et al., J. Nucl. Mater. 385(2009)606-6114.

[10] T. Otsuka and T. Tanabe, J. Alloys and Comp. 446-447 (2007) 655-659.

[11] J. Crank, The Mathematics of Diffusion, (Oxford Univ. Press 1975)

[12] K. Hashizume, J. Masuda, T. Otsuka, et al., J. Nucl. Mater. 367-370 (2007) 876-881

[13] W. G. Perkins, J. Vac. Sci. Technol., 10 (1973) 543.

[14] V. M. Katlinskiy, L. L. Kotlik, Russ. Metall., 2 (1978) 65.

[15] R. E. Stickney, Diffusion and permeation of hydrogen isotopes in fusion reactors: A survey, the chemistry of fusion technology, in: D.M. Gruen Ed.., Plenum, New York, 1972

[16] E. Fromm, E. Gebhardt, Gase und Kohlenstoff in Metallen,Springer, Berlin, 1976

[17] T. Tanabe, T. Yamanishi, S. Imoto, J. Nucl. Mater., 191-194 (1992) 439.

[18] A. P. Zakarov, V. M. Sharapov, E. I. Evko， Soviet Mater. Sci., 9 (1973) 149.

[19] T. Ikeda, et al. This conference

[20] R. Frauenfelder, J. Vac. Sci. Technol., 6 (1969) 388.

[21] C. Garcia-Rosales, P. Franzen, H. Plank, J. Nucl.Mater. 233-237 (1996). 803

[22] P. Franzen, C. Garcia-Rosales, H. Plank, V. Kh. Alimov, J.Nucl. Mater. 241-243 (1997). 1082

[23] T. Otsuka, T. Hoshihira and T. Tanabe, Physica Scripta, T 138 (2009) 014052

[24] V.Kh. Alimov et al, J. Nucl. Mater. 375 (2008) 192-201. 
Figure captions

Fig.1 (a) Photographs of blistered surface of GDC Mo and (b) enlarged one showing surface blisters. IP images (c) immediately after the T loading and (d) 10 month later. Areal tritium intensities are proportional to Photo-Stimulated-Luminescence (PSL) determined by IP.

Fig.2 T evolution for GAS Mo specimen (a) at $293 \mathrm{~K}$ and (b) $323 \mathrm{~K}$. Lines in the figure show fitted theoretical evolution to determine diffusion coefficients assuming a diffusion limited process.

Fig.3 T evolution for GAS W specimen (a) at $293 \mathrm{~K}$ and (b) $323 \mathrm{~K}$. Lines in the figure show fitted theoretical evolution to determine diffusion coefficients assuming a diffusion limited process.

Fig. $4 \mathrm{~T}$ evolution for GDC Mo specimen (a) at $293 \mathrm{~K}$ and (b) $323 \mathrm{~K}$. Lines in the figure show fitted theoretical evolution to determine diffusion coefficients assuming a diffusion limited process.

Fig. 5 T evolution for GDC W specimen at $293 \mathrm{~K}$. Lines in the figure show fitted theoretical evolution to determine diffusion coefficients.

Fig.6 Comparison of diffusion coefficients of hydrogen in Mo. Bold lines are reliable literature data with the extrapolations (dotted lines) to both higher and lower temperature ranges. $\bigcirc$ This work for GAS Mo, $\square$ This work for GDC Mo, $\Delta$ Ikeda et al[19]

(a) T. Tanabe et. al.[17], (b) W.G. Perkins [13], (c) A.P. Zakarov et. al.[18], (d) R.E. Stickney[15], (e) V.M. Katlinskiy et. al.[14], (f) E. Fromm et. al. [16]

Fig.7 Comparison of diffusion coefficients of hydrogen in W. Bold lines are reliable literature data with the extrapolations (dotted lines) to both higher and lower temperature ranges.

- This work for GAS W, $\square$ This work for GDC W, $\Delta$ Ikeda et al[19], (a) R. Frauenfelder [20], (b) A.P. Zakharov et al. [18] , (c) C. G. Rosales et al. [21], (d) P. Franzen et al. [22], (e) T. Otsuka et al. [23]

Fig.8 Comparison of $\mathrm{T}$ evolution based on recombination limited release model shown as bold line, on diffusion limited one shown as thin dotted line and experimental data. 
Corresponding Author Name: Tetsuo Tanabe

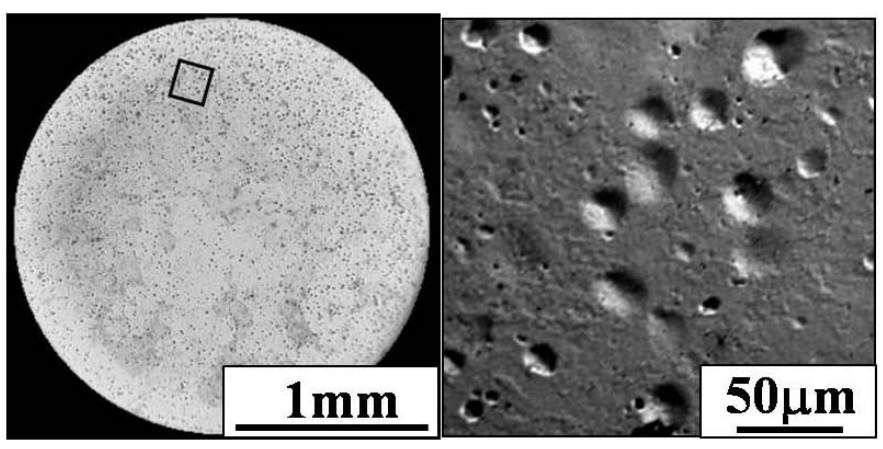

IP image of surface after hydrogen loading

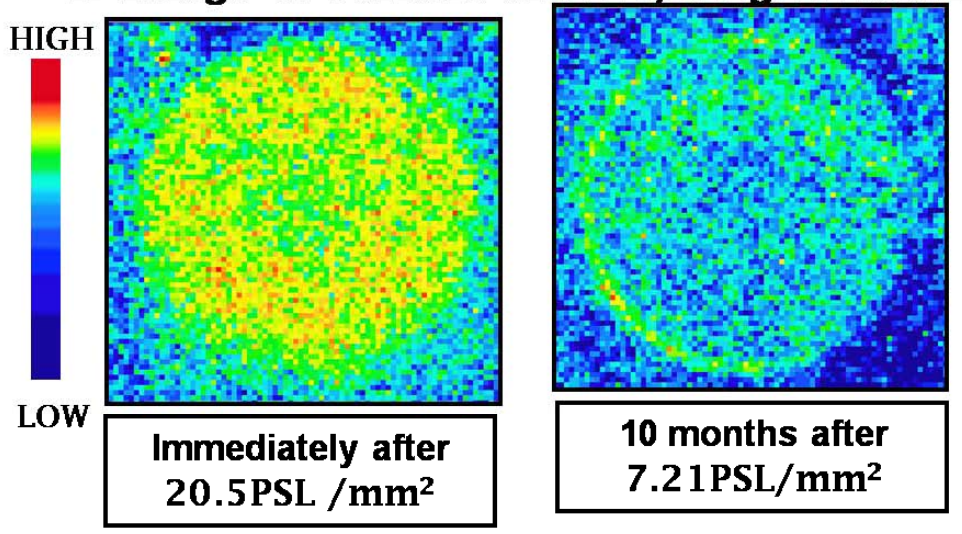

Figure 1

(single column) 
Corresponding Author Name: Tetsuo Tanabe
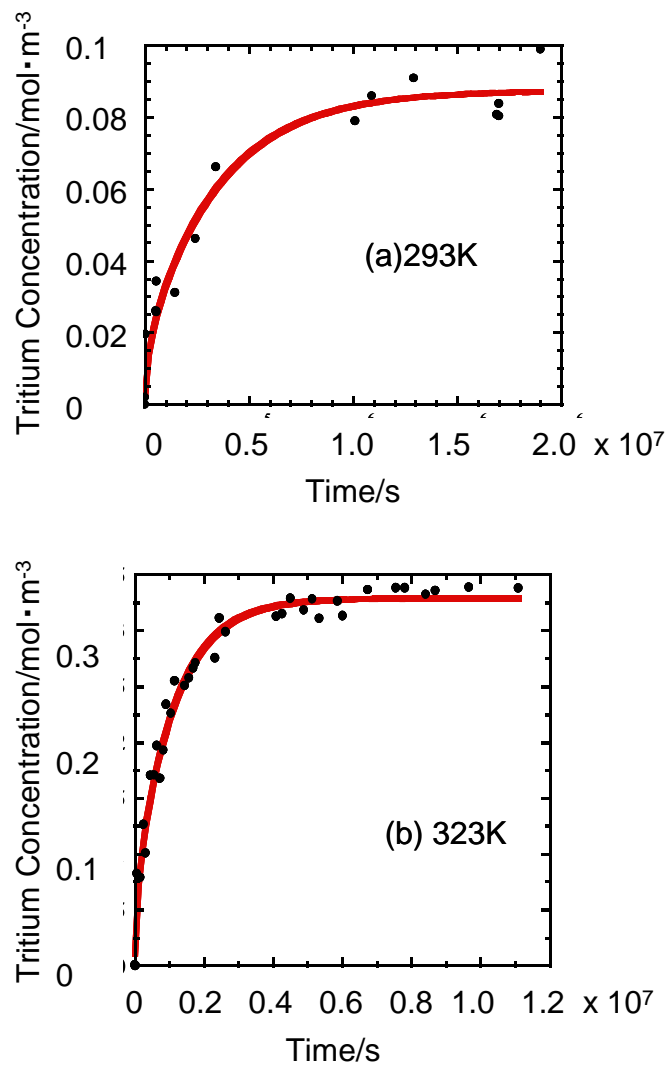

Figure 2

(single column) 

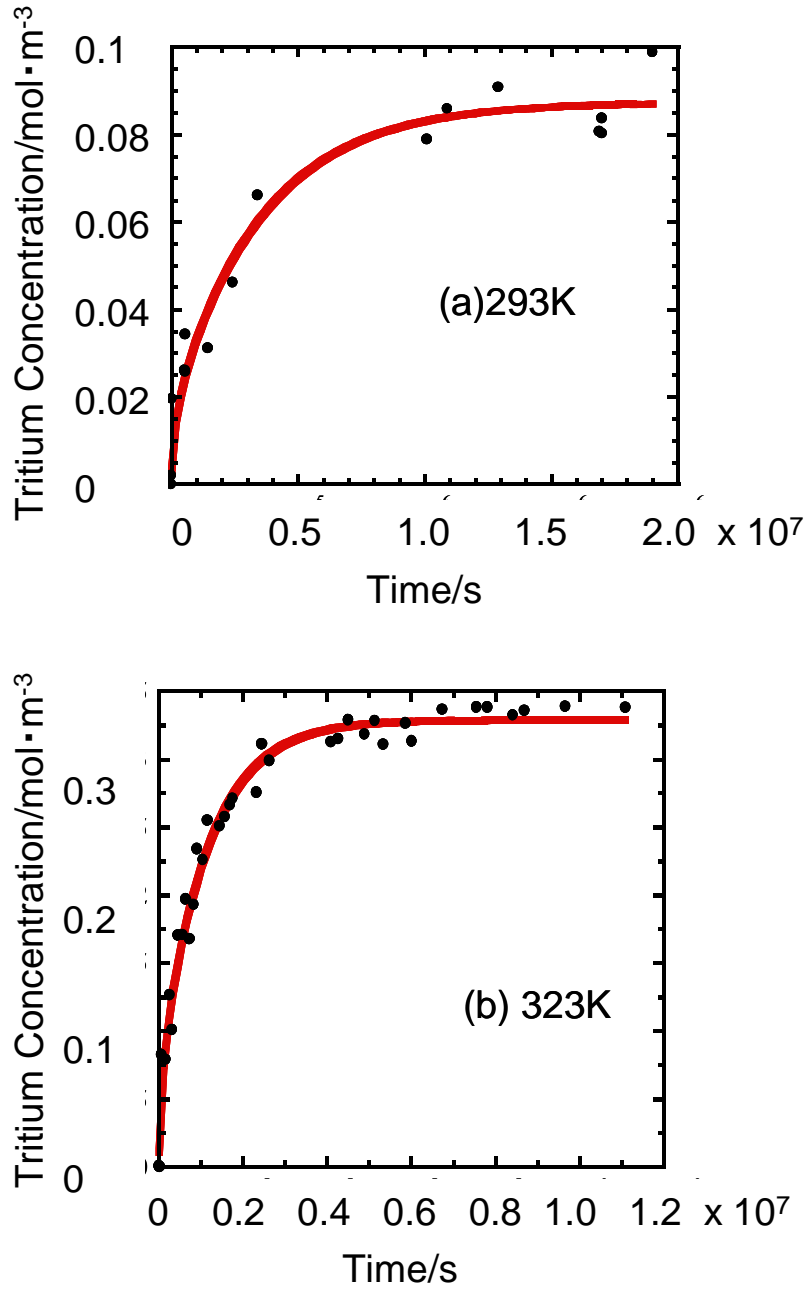

Figure 3

(single column) 
Corresponding Author Name: Tetsuo Tanabe
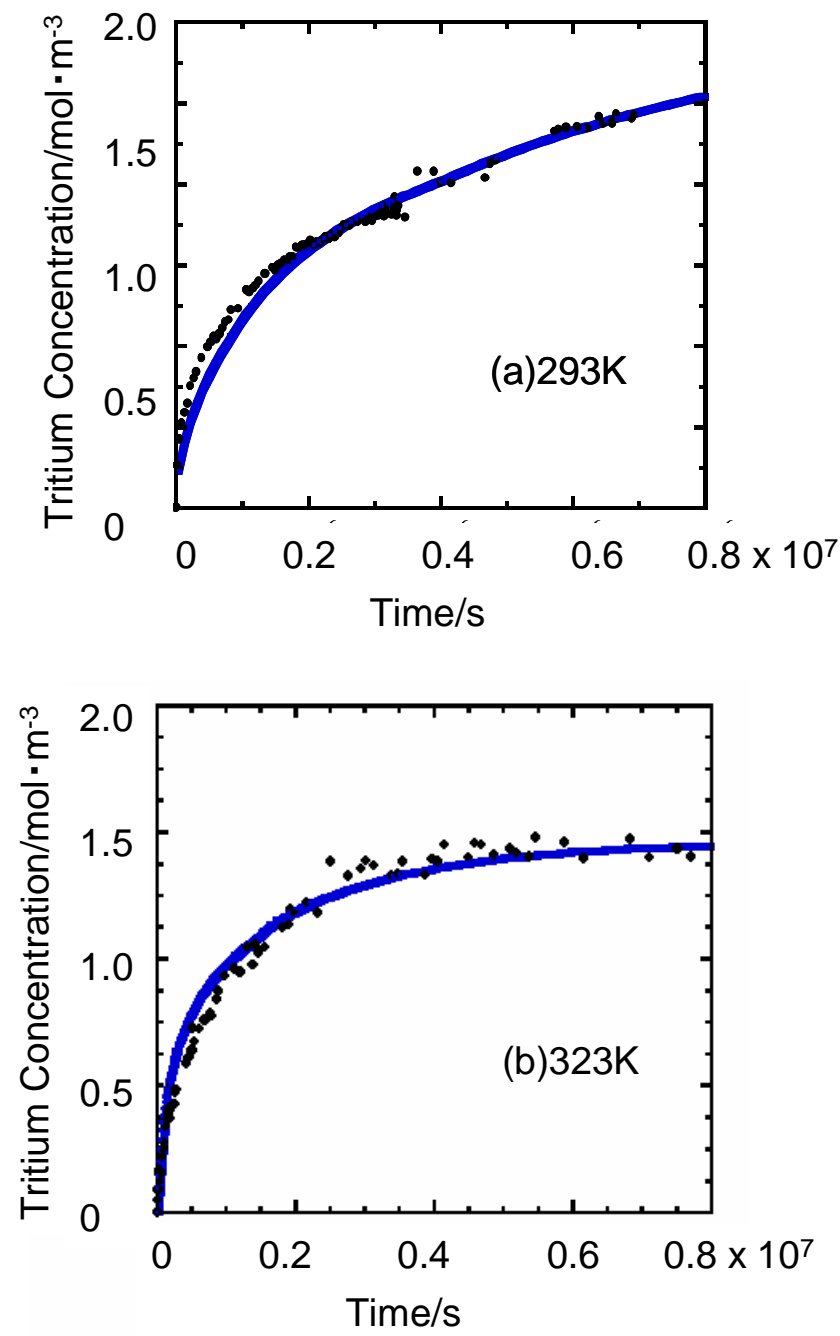

Figure 4

(single column) 
Corresponding Author Name: Tetsuo Tanabe

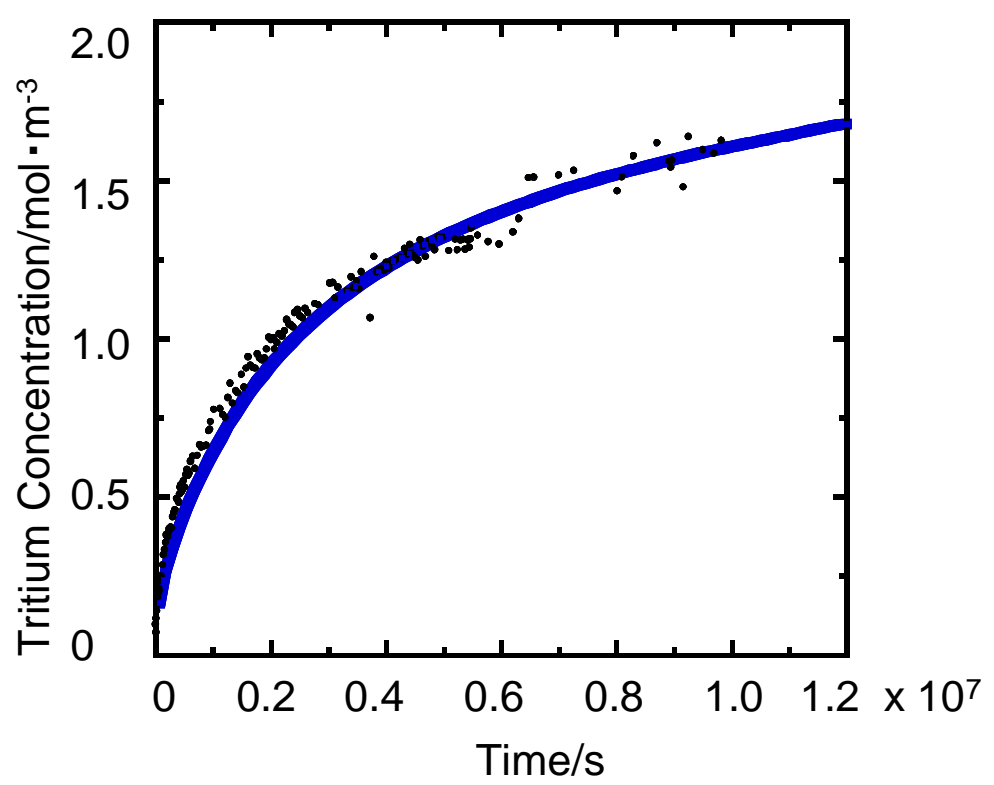

Figure 5

(single column) 
Corresponding Author Name: Tetsuo Tanabe

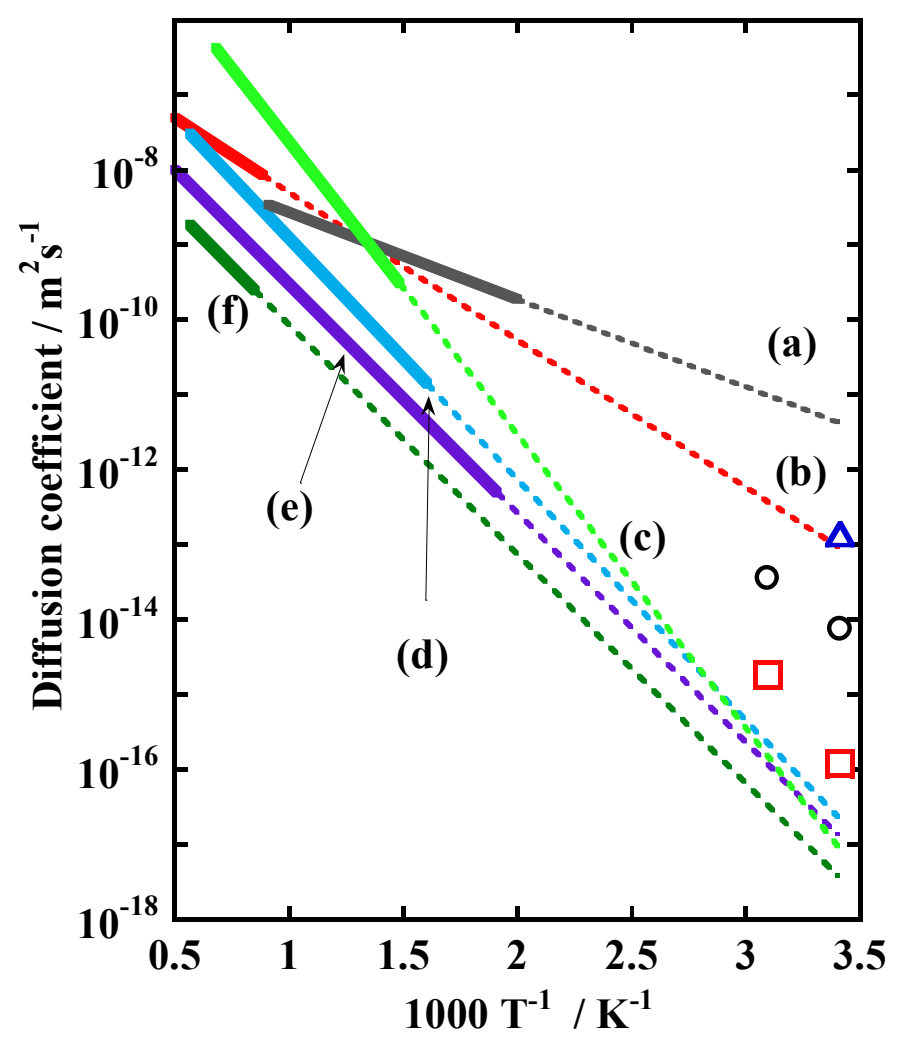

Figure 6

(ssingle column) 
Corresponding Author Name: Tetsuo Tanabe

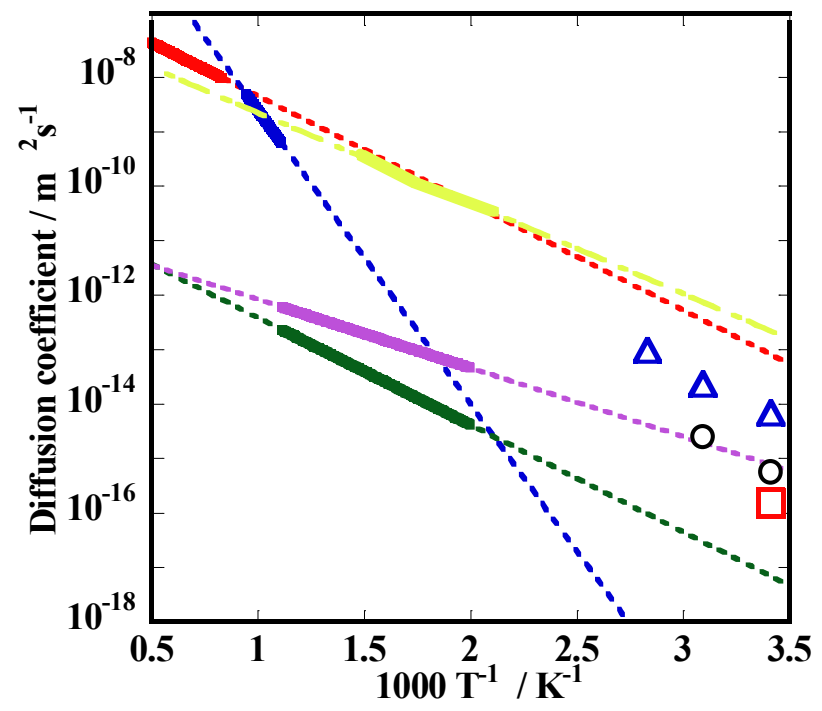

Figure 7

(single column) 
Corresponding Author Name: Tetsuo Tanabe

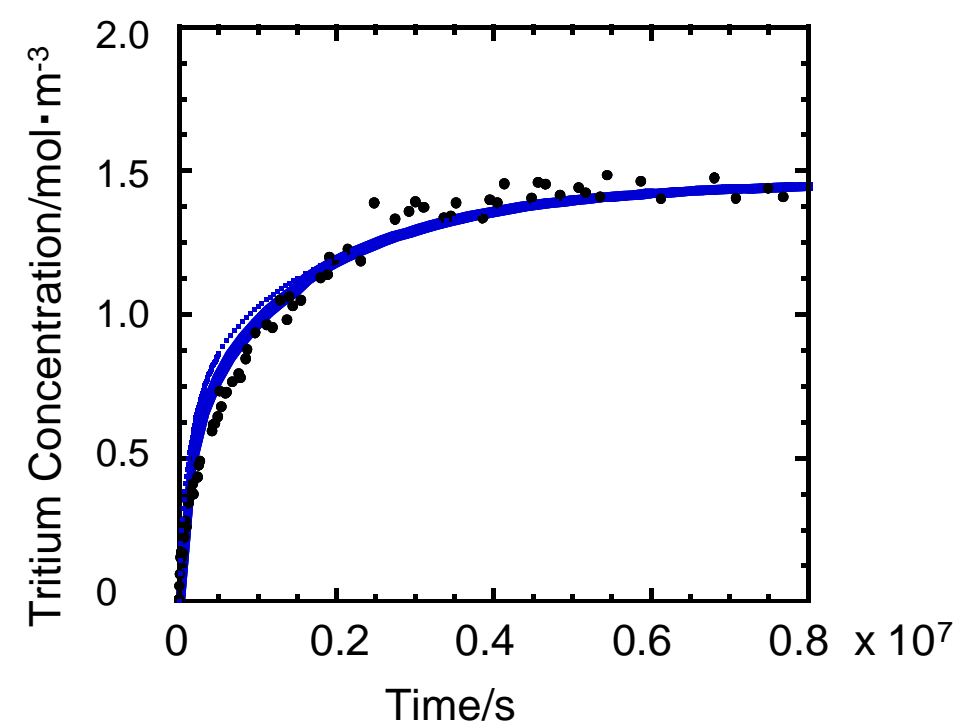

Figure 8

(one column) 
